\title{
A REFORMULAÇÃO DE LIVROS ANALISADA DESDE UM PRISMA DISCURSIVO: identidades em jogo na relação entre versões
}

\author{
Adriana Pozzani de La Vielle*
}

\begin{abstract}
Discourse Analysis (as it is specially developed by Pêcheux, Orlandi and Indursky) is the theoretical base for a discussion about books reformulation and about the statute of the socalled "revised edition". Once we are interested on scientific internal reconfigurations (we mean: those ones which operate on knowledge and on ideological positions), we take books reformulation as a discursive process. Our task in this paper is to observe the authorship work on the linguistic-historical materiality of pairs of editions (the "starting" edition and the revised one), in order to examine, on the one hand, the relations established between the subject-author and the two versions of a book of him, and, on the other hand, the discursive statute of the revised edition. In general lines, our major guide questions for this paper are: how can we discursively think about the revised edition? Is it still the same book? Is it another one disguised upon the same old title? Does it have a contradictory identity? This paper intends to answer these questions.
\end{abstract}

Key-words: Identity, Discourse, Authorship

Resumo: A Análise do Discurso (tal como desenvolvida especialmente por Pêcheux, Orlandi e Indursky) é base teórica para uma discussão sobre a reformulação de livros e o estatuto da chamada "edição revista". Uma vez que nos interessam reconfigurações científicas internas (ou seja: aquelas que operam sobre saberes e posições ideológicas), tomamos a reformulação como um processo discursivo. Nosso propósito, no presente artigo, é observar o trabalho de autoria na materialidade linguístico-histórica de pares de edições (a edição “de partida” e a revista), a fim de examinar, de um lado, as relações entre o sujeito-autor e as duas versões de um livro seu, e, de outro lado, o estatuto discursivo da edição revista. Em linhas gerais, nossas principais questões norteadoras são: como pensar discursivamente a edição revista? Trata-se ainda do mesmo livro? Trata-se de um outro disfarçado sob o mesmo e antigo título? Tem ela uma identidade contraditória? Este artigo pretende responder a essas indagações.

Palavras-chave: Identidade, Discurso, Autoria

\section{INTRODUÇÃO}

À luz da Análise do Discurso (tal como desenvolvida, especialmente, por Pêcheux, na França, e por Orlandi e Indursky, no Brasil), este artigo toma como objeto de investigação o processo discursivo de reformulação de livros. Dada, porém, a imprecisão referencial inerente ao objeto eleito (há reformulações de toda ordem), impõe-se esclarecer que nos interessam, especificamente, reformulações autorais que, efetuadas em livros impressos basilares, incidem sobre metalinguagem ao ressignificar conceitos fundantes e implicam um redimensionamento de determinadas parcelas do saber próprio à ciência no interior da qual o sujeito-autor do livro se situa. No caso do presente artigo, interessa problematizar questões ligadas à identidade da edição revista, a fim de responder às seguintes indagações: como pensar discursivamente essa edição?

\footnotetext{
* Discente do Programa de Pós-Graduação em Letras da UFRGS.
} 
Trata-se ainda do mesmo livro? Trata-se de um outro disfarçado sob o mesmo-antigo título? Estáse diante de um livro cuja identidade é ambígua? Qual a relação do sujeito-autor-revisor com as distintas versões de um livro "seu”?

Dada a natureza deste escrito (qual seja, a de artigo), não pretendemos realizar aqui uma análise exaustiva; ao contrário: não faremos mais do que esboçar uma reflexão em torno do eixo discurso-autoria-identidade. O propósito do presente artigo é, pois, observar o trabalho de autoria na materialidade linguístico-histórica de pares de edições (a edição “de partida” e a revista), a fim de examinar, de um lado, as relações entre o sujeito-autor e as duas versões de um livro seu, e, de outro lado, o estatuto discursivo da edição revista ${ }^{1}$. Evidentemente, tal objetivo conduz à tentativa de capturar os modos pelos quais o sujeito se relaciona com os saberes da formação discursiva (o campo de conhecimento) no interior da qual se inscreve ${ }^{2}$.

Um estudo do processo discursivo de reformulação de livros deve considerar a inscrição da edição revista nas condições sócio-históricas que a instauram e que determinam os modos de apropriação/reprodução/transformação de saberes do campo no qual ela se constitui e do qual ela, de certa maneira, decorre. Ora, num determinado momento, o texto de uma dada edição passa a já não servir, e até mesmo a ser inapropriado, daí decorrendo, então, a necessidade de "atualizar" o livro, desestruturá-lo a fim de reestruturá-lo novamente, desta vez sob outras maneiras. Com isto, cria-se o confronto na hegemonia de saberes que perdem seu posto hierárquico em prol da hegemonia da "nova" parcela de saberes. Pensemos sobre essa questão a partir de reflexões de Ana Zandwais (2005b, p.84), a qual diz o seguinte:

Se não se pode julgar o espírito de uma época somente pelo que ela pensa de si mesma, em virtude de que cada época está impregnada de suas verdades, e, portanto, de suas formas de inclusão de saberes em torno de como se legitimam determinadas práticas sociais/discursivas em detrimento de outras, então é preciso, pelo menos, apreender suas relações de contradição, para que possamos investigar sob que condições determinados saberes tornam-se hegemônicos ou legitimados superestruturalmente e passam a exercer determinadas formas de controle sobre outros.

De certo modo, também aqui se está diante de novos saberes que passam a figurar como hegemônicos nos domínios que os abrigam. Cumpre, portanto, investigar as práticas discursivas que instauram a contradição nas formações discursivas. E diante do que precede, faz-se condição sine qua non para prosseguir fornecer ao leitor um sucinto embasamento teórico quanto aos conceitos e reflexões essenciais à presente discussão.

\section{FUNDAMENTOS EM ANÁLISE DO DISCURSO PARA O EXAME DO PROCESSO DE REFORMULAÇÃO DELIVROS}

Ao abordar a elaboração dos conhecimentos científicos enquanto processo discursivo, Michel Pêcheux, em seu Les Vérités de La Palice (1975, ed.bras. Semântica e Discurso, 1988)

\footnotetext{
${ }^{1}$ Para fins desta análise, mobilizaremos edições da Moderna Gramática Portuguesa (Bechara, 1987; 2005); de Sociedade de classes e subdesenvolvimento (Fernandes, 1968; 1972); da Gramática Normativa da Língua Portuguesa (Rocha Lima, 1959; 1972) e, também, de Estruturalismo e Poética (Todorov, 1970; 1976). Para maiores informações sobre os livros, remetemos o leitor à seção "Referências do corpus", colocada após a bibliografia.

2 Fazemos uma equivalência entre "formação discursiva” e "campo de conhecimento" em virtude de nosso objeto de reflexão. Lembramos, porém, que o conceito de "formação discursiva” (FD) é muito mais complexo em Análise do Discurso: em linhas gerais, diremos que uma FD é definida, nesta teoria, como aquilo que, a partir de uma dada posição ideológica em uma dada conjuntura sócio-histórica, determina o que pode/deve ser dito (Pêcheux, 1975).
} 
afirma que a produção histórica desses conhecimentos não resulta de um mero ato de inovar mentalidades ou de uma criação imaginativa do homem; ela é efeito de todo um processo histórico. E assim, os conceitos de uma dada ciência não possuem exatamente um sentido, mas antes uma dada "função em um processo" (idem, p.193). Segundo Pêcheux, "vão se formando 'respostas' novas a questões que não haviam sido colocadas", processo esse no qual certos "nomes e expressões se apagam", ao passo que outros "aparecem sob o efeito de certos deslocamentos do campo, de certas intrusões 'incongruentes' de elementos 'lançados', desligados-caídos de outros lugares” (idem, p.194). O processo da produção dos conhecimentos diz ele - "está, pois, indissociavelmente ligado a uma luta a propósito de nomes e de expressões para aquilo que eles designam" [...] (Pêcheux, idem, p.197) [grifos nossos]. E a "suposta indiferença" quanto a tais nomes não passa de mito.

Avançando, tratemos de autoria e reformulação. Dado que elabora/reelabora seu texto a partir de um lugar discursivo, o sujeito sofre determinações que são parte do momento histórico em que se situa; tais determinações, embora sejam de ordem interdiscursiva, exercem-se através de uma formação discursiva (FD). Quando da interpelação ideológica, o sujeito apropria-se de saberes que, preexistentes a seu discurso, provêm do interdiscurso. A tomada de posição (indispensável) ocorre simultaneamente à produção do discurso e o faz através de alguma dessas três "modalidades": identificação, contra-identificação e desidentificação, sendo que todas elas envolvem uma relação entre o sujeito produtor de discurso e o Sujeito Universal (ou formasujeito, enquanto organizadora dos posicionamentos possíveis) do domínio de saber no interior do qual se constitui o sujeito. Tais modalidades, porém, "não são evidentes, nem diretamente apreensíveis”, como formas de apropriação/reprodução/transformação de efeitos pré-construídos que dominam os sentidos do dizer do sujeito; elas representam "diferentes modalidades de 'captura' do sujeito em seu processo de assunção de uma identidade” (Zandwais, 2005a, p.145).

A primeira modalidade concebida por Pêcheux (1975/1988), a identificação, refere a superposição entre sujeito e Sujeito; trata-se do "bom sujeito", aquele que reproduz fielmente os saberes. Já o segundo caso, o da contra-identificação, refere uma relação tensa entre sujeito e Sujeito, uma agitação (este é um termo bem apropriado) no interior da FD. Como o nome sugere, a contra-identificação corresponde a uma tomada de posição que duvida, questiona e/ou contesta os saberes da FD; no entanto, o sujeito questionador permanece, mesmo assim, no mesmo domínio de saber, sendo chamado por Pêcheux, em decorrência disso, de "mau sujeito". Essa permanência do sujeito atesta a não-unicidade característica da forma-sujeito. A contraidentificação permite entrever a heterogeneidade na formação discursiva. Por fim, a terceira modalidade corresponde à desidentificação, caso em que o sujeito desliga-se de relações com o Sujeito Universal de um domínio, a fim de migrar para outro campo e, neste movimento, identificar-se, portanto, com outro Sujeito a partir de nova interpelação. Pêcheux (idem) considera que as duas primeiras modalidades - identificação e contra-identificação - ocorrem no âmbito de um único domínio de saber, ao passo que a terceira delas - a desidentificação - implica necessariamente dois, já que envolve a migração do sujeito de um domínio a outro.

Freda Indursky (2008), fazendo de tais considerações pecheutianas a base de sua reflexão, propõe uma releitura dessas três modalidades, releitura essa decorrente do objetivo de refletir acerca da trajetória da categoria sujeito em AD. Indursky acredita que, antes de identificar-se com a forma-sujeito propriamente dita e através dela com a ideologia, o sujeito relaciona-se, na verdade, com parcelas de saber da FD. Para a autora, o fato de a forma-sujeito ser fragmentada e comportar em si a contradição autoriza que se possa considerar a existência de mais do que duas posições possíveis: há uma posição que aparece como dominante, mas há também espaço não para uma, mas para várias outras posições-sujeito que podemos designar como "não-dominantes" 
em relação àquela. Depreende-se das reflexões tecidas por Indursky a possibilidade de haver diferentes posicionamentos coexistentes de contra-identificação passíveis de ser comportados pela forma-sujeito de um campo de saber, e isto em decorrência de singulares modos de relação entre sujeito e ideologia (via tomada de posição).

A questão para Indursky é pensar o caso em que a movimentação de sentidos no interior da FD não chega a induzir a ruptura "radical e definitiva", antagônica mesmo, própria à desidentificação. Daí a proposta de conceber o acontecimento enunciativo. Relacionado à contraidentificação, a qual se dá com a posição-sujeito dominante, o acontecimento enunciativo coloca em cena um novo modo de enunciar no interior de uma FD, modo este que opera pelo viés da tensão e do estranhamento; trata-se, portanto, de um conflito interno, que ocorre em relação aos modos enunciativos de uma dada posição-sujeito (geralmente a dominante).

Avançando, quando a reformulação é - como a que aqui nos interessa - de natureza efetivamente teórica (saberes), e por ela se materializa na edição revista uma busca por elaborar um livro que mais "adequadamente" ressignifique determinada parcela dos saberes próprios a uma dada formação discursiva, então é possível afirmar que se está diante de um acontecimento enunciativo, tal como o elabora Indursky (2008). Neste caso, é preciso desconstruir a edição antiga e construir a nova versão do livro em uma edição dita "revista", procedimento esse que coloca em cena a tensão simultânea entre aquilo que, parafraseado (ou reproduzido ipsis litteris) permanece na mesma matriz de sentido, e aquilo que, deslocado, implica efetivamente a reformulação, ou seja, um modo totalmente outro de enunciar. Indissociavelmente, as ilusões de que "isto é meu" e "eu digo (ou reformulo) isto desta forma" caracterizam o modo pelo qual o sujeito-autor-revisor é afetado pelo jogo entre memória e esquecimento, no momento em que o texto objeto de reformulação (a edição antiga) apresenta-se a ele enquanto um "acontecimento a ler" (Pêcheux, 1983/1999) ${ }^{3}$.

Eni Orlandi (2001, p.65) acredita que as versões mostram "uma relação que não é rígida nem definitiva com as formações discursivas: as margens das diferentes versões exibem difíceis limites fluidos e cambiantes na relação das formações discursivas”. Pode-se deslocar isto e dizer que revelam a heterogeneidade da forma-sujeito no âmbito de uma única FD. É inerente a todo texto, segundo a autora, a possibilidade de diferentes formulações e reformulações possíveis; há textos possíveis nas margens do texto. Ocorre que as diferentes versões de um texto não se dispersam isoladamente; ao contrário, formam redes de memória em relação àquilo que é dito novamente e reformulado. O novo livro, decorrente do processo de reformulação, constrói-se a partir de já-ditos e situa-se em relação a um dado contexto sócio-histórico que, simultaneamente, induz, constitui, marca suas condições de produção (Silva, 2009).

\section{ACONTECIMENTO ENUNCIATIVO E CONTRADIÇÃO NO PROCESSO DISCUSIVO DE REFORMULAÇÃO}

O acontecimento enunciativo - concebido por Indursky (2008) enquanto um novo modo enunciativo que instaura conflito interno na formação discursiva em que emerge - é inerente à elaboração da edição revista. Portanto, só há edição revista (tal como a temos entendido aqui), porque houve um acontecimento enunciativo que passou a impedir a identificação subjetiva com algumas parcelas de saber anteriormente formuladas na edição de partida. Esse acontecimento, então, manifesta-se de diferentes modos na materialidade discursiva da edição revista; entre eles,

\footnotetext{
${ }^{3}$ A questão do "acontecimento a ler” é trabalhada por Pêcheux em "Rôle de la mémoire” (1983, trad.bras. "Papel da memória”, 1999).
} 
elegemos para este artigo a forma da contradição, como veremos a seguir. Vale esclarecer que, metodologicamente, utilizaremos as notações: R para "recorte"; EP para referir a "edição de partida"; ER para referir a "edição revista"; e o símbolo $\varnothing$ para indicar a ausência (em EP ou ER) de uma formulação passível de comparação com aquela que está em análise.

\subsection{Embates com modos de enunciar}

Deve-se dizer que nem sempre a mudança imposta é compatível com a posição teórica do sujeito-autor-revisor, e tal situação cria um embate do qual as notas do Autor e os prefácios costumam ser o palco privilegiado. Observem-se os dois recortes abaixo, ambos extraídos de edições da Gramática Normativa da Língua Portuguesa, de Rocha Lima (1959; 1972):

R1

EP - Por já existir notável convizinhança entre a terminologia nele adotada desde a primeira edição e a que houve por bem preferir a norma oficial, foi-nos empresa sobremodo fácil - no caso de simples opção entre nomes - proceder a completo reajustamento, que realizamos no próprio corpo da obra./ Mas, como é notório, as questões de NOMENCLATURA muita vez se entrelaçam às de DOUTRINA; e, então, não é lícito a ninguém renunciar - por mais que sejam dignos de louvor os propósitos da unificação preconizada pela boa política do ensino./ Para satisfazer este último aspecto, deliberamos relacionar à parte, num APÊNDICE, as passagens (aliás, muito poucas) da Gramática Normativa que, por mergulharem raízes em matéria de ordem doutrinária, não coincidem, em pormenores, com algumas facetas teóricas implícitas em meia dúzia de pontos da Nomenclatura Gramatical Brasileira./ Assim se conciliam, ao parecer, a utilização didática do livro e as linhas-mestras das convicções do Autor. (Rocha Lima, 1959, p.1-2) [todos os grifos em itálico e caixa alta são de Rocha Lima] $\mathrm{ER}-\varnothing$

R2

$\mathrm{EP}-\varnothing$

ER - A partir de certa altura de sua jornada, teve este livro o texto estereotipado, e, pois, irrefundível./ Em razão disso, não pôde o Autor, muito a seu malgrado, carrear para a obra novas idéias, novas doutrinas, novos métodos - enfim, a visão nova que passou a ter, [...]. (Rocha Lima, 1972, No Liminar - desta $15^{a}$ edição - p.X)

Desde a edição de 1959, já se pode ver materializada na Gramática Normativa da Língua Portuguesa, de Rocha Lima, a contra-identificação do sujeito-autor quanto a uma dada parcela de saberes; no caso, trata-se das normas impostas pela Nomenclatura Gramatical Brasileira (NGB). Neste sentido, R1 revela o conflito de um sujeito dividido entre dois posicionamentos, quais sejam: o do sujeito que realiza as alterações que dele se espera - ou seja, o "bom-sujeito" pecheutiano que obedece às imposições da NGB - e, no mesmo texto, o do sujeito que contesta certas normas do documento oficial - logo, o "mau-sujeito" pecheutiano, relido por Indursky (2008) como o sujeito que, ao se contra-identificar com certa parcela de saberes, instaura um acontecimento enunciativo, na medida em que seu trabalho opera na/sobre a forma-sujeito. Linguisticamente, vemos que, na EP, a conjunção "Mas” é a responsável por denunciar esse conflito ideológico; veja-se: a formulação "foi-nos empresa sobremodo fácil - no caso de simples opção entre nomes - proceder a completo reajustamento, que realizamos no próprio corpo da obra" é imediatamente seguida, em novo parágrafo, por "Mas, como é notório, as questões de NOMENCLATURA muita vez se entrelaçam às de DOUTRINA; e, então, não é lícito a ninguém 
renunciar - por mais que sejam dignos de louvor os propósitos da unificação preconizada pela boa política do ensino” (Rocha Lima, 1959, p.1) [itálico nosso; caixa alta de Rocha Lima].

Gostaríamos de resgatar aqui algumas considerações pecheutianas trazidas na Introdução do presente artigo: trata-se de lembrar o fato de que o processo de produção dos conhecimentos encontra-se "indissociavelmente ligado a uma luta a propósito de nomes e de expressões para aquilo que eles designam" [...] (Pêcheux, 1975/1988, p.197) [grifos nossos]. Resulta daí a afirmação deste autor de que a neutralidade científica é nada mais que um mito e, logo, não há qualquer "indiferença com respeito às palavras" (ibid.). Ora, de acordo com Pêcheux, há sempre uma tomada de posição implicada por essa "luta".

O que dissemos no parágrafo acima é claramente constatável no R1, do qual estamos falando: vê-se que a contra-identificação do sujeito instaura um confronto a propósito de conceitos/definições que um posicionamento ideológico $X$ (e não outros) permite atribuir a uma dada categoria Y. Ou seja: lá onde "as questões de NOMENCLATURA muita vez se entrelaçam às de DOUTRINA” (Rocha Lima, 1959, p.1) [caixa alta do autor], subjazem certas tomadas de posição que, por sua vez, têm cada qual o seu modo próprio de construir e de significar a metalinguagem própria à Gramática. É por isso, aliás, que em certas Gramáticas (a de Bechara, por exemplo) pode-se encontrar o vocábulo "não” como advérbio de negação e, em outras - aí incluídas a de Rocha Lima -, isto não acontece. O que dizer sobre as implicações disto? Mais uma vez, lembremos Pêcheux: não há discurso científico puro, porque todo discurso é ideológico ao resultar de tomadas de posição.

A importância de problematizar o que ocorre na EP é essencial para que se compreenda o quanto isso permanece implícito na edição revista, a qual não comporta nem a advertência (da qual se extraiu R1) e, tampouco, o Apêndice que explicita as implicações, para a Gramática, da contra-identificação do sujeito-autor. Dadas as referidas ausências, a contra-identificação do sujeito-autor quanto à NGB é materializada, na ER, apenas no interior dos capítulos (retornaremos a este ponto um pouco mais adiante). Passando, então, ao recorte 2, vê-se que também ele toca em questões de convicção teórica, ao lembrar a trajetória de elaboração ainda da Gramática de Rocha Lima. R2, especialmente, revela que o sujeito não é livre para dizer o que quiser, na medida em que há um controle sócio-histórico sobre a produção do livro. Retome-se deste recorte o que se segue: a partir de uma determinada "altura de sua jornada" - afirma Rocha Lima na edição revista - "teve este livro o texto estereotipado, e, pois, irrefundível./ Em razão disso, não pôde o Autor [no caso, ele próprio], muito a seu malgrado, carrear para a obra novas idéias, novas doutrinas, novos métodos - enfim, a visão nova que passou a ter” (1972, p.X).

Se, conforme diz Pêcheux no trabalho "Lire l'archive aujourd'hui” (1982, trad.bras. "Ler o arquivo hoje”, 1997), há formas de controle da leitura e da interpretação (estas últimas não podem ser quaisquer umas), então há, igualmente, formas de controle da produção e circulação de livros - o que, aliás, já está bem desenvolvido, fora da AD, por Michel Foucault em $L$ 'ordre du discours (1971, ed.bras. A ordem do discurso, 2006), por exemplo. Voltando ao recorte 2, podese facilmente perceber que, na conjuntura específica da edição de 1972, há um conflito desfeito, na medida em que a conjuntura em tela, ao contrário da anterior, já possibilita ao autor introduzir modificações. A interdição do novo - avesso daquilo que se costuma observar no processo de reformulação, afinal, costumam-se interditar saberes anteriores, não novos - cede enfim lugar à interdição do antigo, e o sujeito-autor vê-se agora "livre" (isto, sabe-se, é ilusão em AD) para enunciar inclusive sua discordância quanto às imposições colocadas pelas diferentes conjunturas da produção de cada uma das edições.

A tensão entre a posição dominante e aquela que a esta se contra-identifica (sobretudo no R1) atesta que a reprodução de sentidos no interior de uma FD sinaliza diferentes modos de 
relacionamento com a ideologia. Pode-se deslocar - a partir da observação dos dois recortes acima - o que dissera Pêcheux (1975/1988) acerca do papel que têm os conceitos em um dado campo de conhecimentos: eles possuem uma função em um processo. Esse autor afirma isso pensando o fato de que a elaboração de conceitos inaugura um campo no âmbito de todo um processo histórico que o engendra. Para o caso aqui examinado, considerar a historicidade da edição revista permite dizer que se a conceituação não desempenhasse papel tão fundamental, não seria o aspecto mais afetado pela reformulação e o foco do estranhamento entre sujeito-autor (ao qual se liga o nome de Rocha Lima) e a instituição referida indiretamente por "a norma oficial” e por "Nomenclatura Gramatical Brasileira”. Notadamente, o sujeito-autor-revisor não é completamente submisso à totalidade da parcela hegemônica (representada pela NGB, cf. R1) que impõe, sob a forma de Portaria Ministerial, o que deve ser dito. E o mais interessante é que, nesta, se pode ler que Rocha Lima é um dentre os nomes designados pelo Ministério da Educação e Cultura, com vistas a estudar e propor, para fins didáticos, um "projeto de simplificação e unificação da nomenclatura gramatical” (Rocha Lima, 1959, p.581-582); é, pois, em decorrência desse fato que nascem as polêmicas de ordem teórica. Como se vê, certamente não houve um consenso entre os diferentes gramáticos designados para unificar a nomenclatura gramatical.

Os recortes acima fazem ver a importância que a atribuição de sentidos a esta ou àquela categoria assume na teorização. Pensando essa questão de um modo mais geral, vê-se que isso sinaliza para o fato de que, na produção de conhecimento, costuma haver interdições. Há, por exemplo, uma proibição a nomear de outro modo certa categoria, quando não até mesmo (e este é o nosso posicionamento) uma espécie de "tabu teórico": há muito mais do que apenas palavras que significam diferentemente conforme se inscrevam neste ou naquele campo, ou sejam ditas segundo este ou aquele posicionamento. Há, de fato, palavras que não se podem enunciar no interior de um campo X. Há, decerto, efetivas proibições léxico-ideológicas funcionando subterraneamente no processo que engendra uma edição revista, mas também, e de modo geral, nos vários gestos de produção de conhecimento.

As relações de poder instauradas no discurso atestam que, apesar de o processo discursivo de reformulação de livros decorrer de exigências imputadas ao sujeito-autor, as questões sociais, teóricas e pedagógicas implicadas pelo referido processo não se sobrepõem à posição teórica daquele que responde pelo livro X (este enquanto uma unidade coerente) e pelos saberes que ali figuram: evidentemente, é sempre um renomado gramático o mais autorizado a escrever edições de Gramática, e ele não quererá ver a si atribuídos modos de dizer não defendidos como válidos. Nessa direção, lembre-se que a autoria enquanto função assumida por um sujeito é, segundo Orlandi (2007), aquela que está mais determinada pela exterioridade, ou seja, pelo contexto sócio-histórico: "Sendo a autoria a função mais afetada pelo contato com o social e com as coerções, ela está mais submetida às regras das instituições e nela são mais visíveis os procedimentos disciplinares" (idem, p.75). Conforme Orlandi, "a assunção da autoria implica uma inserção do sujeito na cultura, uma posição dele no contexto sócio-histórico” (idem, p.76).

A reformulação, como se vê, não incide apenas sobre o gesto de trocar este ou aquele termo, acrescentar/suprimir esta ou aquela passagem; incide, notadamente, sobre a urgência de repensar aspectos que concernem às próprias bases teórico-epistemológicas do campo em questão e, assim, redefinir o enunciável ali (o espaço do dizível da FD). É a partir daí que se reformula o texto do livro, com vistas a disponibilizar ao sujeito-leitor um contato com avanços teóricos engendrados por novas pesquisas que, presume-se, nem sempre sejam acessíveis (por questões de escolaridade e/ou de ordem geográfica e econômica) ao público-leitor para o qual se destinam as edições aqui examinadas. 
É verdade que ainda há certa parcela de saberes “antigos” repetíveis; porém, a ênfase que temos buscado imprimir à contra-identificação, aqui abordada pelo viés do acontecimento enunciativo, resulta de nossa crença em que o processo discursivo de reformulação de livros concede primazia à emergência do novo, propriamente, e não àquilo que se repete. O novo modo de enunciar, uma vez instaurado no domínio de saber em que irrompe, atesta o atual posicionamento que o sujeito-autor-revisor passa a assumir. Tal assunção traz a possibilidade da produção de novos sentidos não só ao campo teórico, mas à materialidade da edição revista (visto que esta, de certa maneira, o representa linguístico-historicamente).

Atravessado por $n$ discursos, o sujeito desprende-se de seu lugar de autor a fim de ocupar o de leitor e, a partir daí, reformula o texto desde um novo posicionamento ideológico e uma nova conjuntura sócio-histórica. A função-autor é, portanto, exercida a partir do lugar em que o sujeito se faz leitor de si mesmo. E o texto é reformulado sob a indissociável atuação de dois “esquecimentos” (Pêcheux, 1975/1988): 1) o sujeito não é origem absoluta do texto que ele produz; e 2) há outras $n$ possibilidades de (re)formular o que é dito. Logo, em AD, uma formulação como "Temos consciência de que ainda há muito que acrescentar e rever", de Bechara, não nos isenta de ainda poder afirmar que no processo discursivo em análise atua também uma "força" de natureza inconsciente, cujo controle escapa ao sujeito.

Enunciar o que precede vincula-se à urgência de esclarecer que o processo discursivo aqui tomado como objeto de reflexão tem o seguinte estatuto: se, por um lado, ele não é inteiramente insconsciente, por outro, ele tampouco é totalmente consciente. Há, pois, um jogo entre essas duas "forças", apesar da ilusão subjetiva de controle do dizer, a qual, como se sabe em AD, domina o trabalho de autoria de todo sujeito produtor de texto (incluindo, é claro, o sujeito-autorrevisor, que produz de fato um novo texto, uma nova versão).

As justificativas pela existência da nova edição viabilizam tangenciar o processo de interpelação que permite ao sujeito apropriar-se de novas parcelas de saber e, num movimento simultâneo, desapropriar-se de parcelas antigas, pelo viés da contra-identificação ${ }^{4}$. Notas do Autor e prefácios possibilitam entrever as transformações por que passou o domínio de saber (FD) no interior do qual se inscreve (e se constitui) o sujeito. Como o sujeito se justifica perante o leitor, a respeito do "novo" livro que ali se encontra? Trata-se ainda, de certa maneira, do mesmo livro? Está-se, efetivamente, diante de um outro? É o que veremos através dos recortes a seguir.

\subsection{A reiteração do mesmo na relação entre edição de partida e edição revista}

O recorte abaixo permite refletir sobre as relações entre o mesmo e o outro no caso em que a ênfase indiretamente recai sobre a ideia do mesmo:

R3

$\mathrm{EP}-\varnothing$

ER - A partir de certa altura de sua jornada, teve este livro o texto estereotipado, e, pois, irrefundível. [...] Mantivemos-lhe, decerto, a fisionomia original com que [a Gramática] fora planejada e redigida, a fim de que se lhe não deformasse a inteiriça estrutura intelectual e didática; mas, além da correção de um deslize aqui, da atualização de um conceito ali, e, até, da substituição integral de alguns capítulos e acrescimento de outros, enriquecemos

\footnotetext{
${ }^{4}$ A menção à referida simultaneidade inspira-se em um deslocamento das considerações pecheutianas, segundo as quais a desidentificação (inexistente aqui) quanto a um domínio de saber ocorre ao mesmo tempo em que há identificação com outro. Por certa analogia que parece ter fundamento, defende-se, pois, que a contra-identificação com certas parcelas de saber também é simultânea à nova identificação com parcelas outras.
} 
copiosamente a exemplificação dos 'fatos' da língua, a qual estendemos aos escritores de nossos dias. (Rocha Lima, 1972, No Liminar - desta 15ª edição - p.X)

Inicialmente, fala-se da trajetória do livro como se ele tivesse sempre sido o mesmo; adiante, são mencionados aspectos que o tornam diferente, o que poderia parecer contraditório à primeira vista. Defendemos, porém, que a formulação a respeito do cuidado em manter a "fisionomia original" com a qual o livro havia sido planejado e redigido, permite afirmar que, no fundo, o sujeito assume um posicionamento segundo o qual não deseja, ou mesmo pensa, que o livro em questão seja outro, distinto daquele que vinha sendo até então. Isto permite ver bem a dissimulação do outro no um, ou seja, do diferente no mesmo. Avançando, é possível dizer que a ilusão de que se está diante do "mesmo" livro resulta do efeito-autor. Pensar o mesmo é pensar o fechado; no entanto, o que confere essa aparente unidade que permite tomar o livro como tal é a autoria. Nessa direção, trata-se de um efeito de autoria, na medida em que, embora não haja de fato um fechamento para o texto, há a exigência social de que alguém responda pela suposta unidade e pela coerência de um trabalho que não pode, verdadeiramente, transformar-se em um outro livro. Ora, é justamente o efeito de fechamento que permite ao sujeito reconhecer-se enquanto autor do livro (ou da unidade de sentido) que ali está.

Se o recorte acima permitiu entrever o modo como a responsabilização social que incide sobre o sujeito-autor leva à ilusão de que um livro, apesar das modificações realizadas, pode ainda ser o mesmo, há casos, porém, nos quais isto aparece mais dissimulado (cf. R4, a seguir), ou nos quais o sujeito assume um posicionamento oposto e, vacilando ou não, afirma que o leitor efetivamente está diante de outro texto (cf. recortes 5 e 6).

\subsection{A afirmação do diferente na relação entre edição de partida e edição revista}

Há no processo discursivo aqui analisado um aspecto interessante: em certa medida, o sujeito não precisaria negar uma edição que lhe é atribuída e que ele, de fato, produziu. No entanto, ele deve negá-la em virtude da nova conjuntura sócio-histórica, que, ao mesmo tempo, tanto lhe impõe os meios de produzir uma edição revista, quanto lhe exige que anule de alguma forma a edição anterior (a qual já está ultrapassada). Observem-se os recortes:

\section{R4}

EP - Este livro reúne ensaios que foram escritos sob grande tensão intelectual e moral. O golpe de Estado de 1964 não me apanhou desprevenido. Todavia, como outros intelectuais, não tive meios concretos para fazer algum tipo de oposição válida e eficaz à ditadura militar, que então se estabeleceu. Onde e quando surgiram oportunidades, procurei aproveitá-las, manifestando o meu inconformismo diante da ruptura com as pequenas e superficiais conquistas do regime democrático em nosso País. (Fernandes, 1968, p.7). $\mathrm{ER}-\varnothing$

R5

EP - Isso significa que os ensaios reunidos neste livro não pretendem vincular-se a uma ideologia nem a qualquer filosofia política. Embora socialista convicto, não pretendia fazer socialismo ao escrevê-los. Vários colegas, que não são socialistas ou, mesmo, outros que são contrários ao socialismo, concordaram repetidas vezes com as idéias ou conclusões neles expostas (Fernandes, 1968, p.14).

$$
\text { ER - Ø }
$$




\section{R6}

$\mathrm{EP}-\varnothing$

ER - $\underline{O}$ texto que se segue é bastante diferente do que, escrito em 1967, figurava sob o mesmo título [...]. A razão disso é dupla: o campo da Poética não é mais hoje o que era há seis anos e eu próprio não o encaro sempre da mesma maneira. Mas um texto totalmente novo não poderia mais integrar-se em nosso projeto inicial. Preservei, portanto, a intenção geral e o quadro da primeira versão [...], modificando, contudo, o enunciado cada vez que isso se tornou necessário para prestar contas do atual estado da Poética. (Todorov, 1976, p.7)

R7

$\mathrm{EP}-\varnothing$

ER - Amadurecido pela leitura atenta dos teóricos da linguagem, da produção acadêmica universitária, das críticas e sugestões gentilmente formuladas por companheiros da mesma seara e da leitura demorada de nossos melhores escritores, verá facilmente o leitor que se trata aqui de um novo livro. Dificilmente haverá seção da Moderna Gramática Portuguesa que não tenha passado por uma consciente atualização e enriquecimento [...]. (Bechara, 2005, p.19)

Comecemos pelos recortes 4 e 5, compostos por formulações extraídas do Prefácio de Sociedade de Classes e Subdesenvolvimento, de Florestan Fernandes, Prefácio esse que figura apenas na EP. O apagamento, na ER, do Prefácio da edição anterior (bem como a inexistência de outro que lhe substitua) caracteriza o apagamento de explicações acerca das condições de produção de cada um dos ensaios que compõem o livro. Relegam-se, pois, ao silêncio a tensão moral/intelectual, o contato com certas pessoas, o grau de recepção em eventos, os objetivos básicos. Diante de tão curto intervalo temporal entre uma edição e outra (1968-1972) ${ }^{5}$, interessa lembrar que EP foi publicada no mesmo ano em que ocorreu a imposição do AI-5, o qual, marcando o período mais cruel do regime militar, estendeu-se até 1979. Como se vê, também a ER não escapou de ser produzida sob a vigência do militarismo, o qual, alegando livrar da corrupção/subversão o Brasil, promoveu uma série de indigestos episódios sobretudo no meio acadêmico, onde muitos professores, técnicos e alunos tiveram suas carreiras violentadas, se não estraçalhadas pelo regime ditatorial. Ora, diante de tal contexto, é bastante compreensível que um Prefácio do porte daquele de Fernandes - quanto a isto, observe-se o R5 - seja apagado em nome de um "silêncio" político favorável à publicação dos ensaios comportados pelo livro em pauta.

Passando agora aos recortes 6 e 7, temos em ambos o caso em que o sujeito-autor-revisor pontua claramente sua contra-identificação com o posicionamento que ele próprio assumira na EP, e, com isto, coloca de modo explícito o fato da nova conjuntura. Ou seja: nesses dois recortes, figura o alerta de que o texto da ER é, na verdade, um outro, diferente daquele da EP e assumido como algo que é, de fato, uma reelaboração. Seguindo a ordem de apresentação dos recortes, falemos primeiramente do R6, cujas formulações provêm da "Nota sobre esta edição", escrita por Todorov para a edição revista de Estruturalismo e Poética (1976). É dominante, neste recorte, o lugar de entremeio de um sujeito-autor-revisor oscilante entre dizer do mesmo e dizer do outro, na medida em que há um limite para a diferença, senão o texto já não poderia inscreverse em um "projeto inicial” semelhante ao da versão anterior (qual seja, pensar a Poética em sua relação com o Estruturalismo).

Veja-se a formulação de Todorov (1976): “o campo da Poética não é mais hoje o que era há seis anos e eu próprio não o encaro sempre da mesma maneira” (R6). Constata-se, a partir daí, o

\footnotetext{
${ }^{5}$ Essas datas referem o ano da publicação das versões de Sociedade de classes e subdesenvolvimento, de Fernandes.
} 
fato de que antes mesmo de revelar um compromisso social com o sujeito-leitor e com a produção de conhecimento, o processo de reformulação sinaliza o compromisso do sujeito-autor com sua própria condição. Isto porque tal sujeito só se reconhece como autor se aquilo que ele produz lhe aparece como algo de que se possa enunciar: "faz sentido publicar isso"; ora, EP já não se enquadra mais neste perfil. Nessa direção, a grande problemática colocada pelo processo discursivo aqui investigado é: até onde se pode, ou não, ultrapassar os limites da "identidade" de um livro? Como se pode constatar, a maioria dos sujeitos assume o posicionamento segundo o qual, embora as edições sejam distintas, o livro permanece o mesmo. Inclusive Todorov se inclui nessa posição, já que pontua o fato de que um texto totalmente novo não procederia.

Bechara, porém, parece assumir o posicionamento que categoricamente situa a edição revista como um livro verdadeiramente outro. Observe-se o R7, cujas formulações figuram no Prefácio escrito por Bechara à $37^{\mathrm{a}}$ edição (a edição revista, justamente) de sua Moderna Gramática Portuguesa (2005). A afirmação de que se trata efetivamente de um outro livro em nada semelhante à edição anterior (como se lê em "verá facilmente o leitor que se trata aqui de um novo livro") permite flagrar mais facilmente o novo acontecimento enunciativo que se instaura no interior da formação discursiva. Neste caso (mas também nos demais, é evidente), o sujeito-autor-revisor se situa entre modos distintos de enunciar saberes de seu domínio específico.

A análise dos diferentes posicionamentos assumidos pelos sujeitos viabiliza alcançar o funcionamento da forma-sujeito, que é heterogênea, de cada uma das formações discursivas em questão (a saber, as FDs: Sociologia, Poética e Gramática, respectivamente), no modo como esse funcionamento se vê subordinado a condições de ordem sócio-histórica (ideológica, mas também jurídica e mesmo econômica, para citar alguns fatores). Vê-se que Prefácios e Notas do Autor constituem-se em espaços privilegiados para observação das diferentes relações entre sujeitos, livros, saberes. Orlandi, por exemplo, ao examinar as reedições sobre o "descobrimento" do Brasil elaboradas por outros sujeitos que não os autores das obras "originais", afirma que tais reedições comportam, majoritariamente, "um aparelho crítico, composto de prefácios e notas que remetem ao fio dos textos originais” (1990, p.102). Esse aparelho, se, por um lado, pretende extrair desses documentos aquilo que ali "apresentaria um interesse científico, descartando as 'fantasias' (notadamente pela confrontação dos relatos uns com os outros), ou procurando corrigir o viés induzido pela ótica religiosa e política dos missionários”, por outro lado, direciona a leitura apenas em âmbito do discurso europeu da "descoberta" do Brasil. Acreditando que as notas e prefácios constituem um "discurso paralelo" e posterior, sob a forma de suplementos ou "acréscimos marginais ao texto", Orlandi aponta que

Cada reedição resulta em um outro discurso que trabalha os limites (o início e as margens) do texto, ou melhor, da formação discursiva constituída pelo discurso sobre as descobertas. [...] Dada a mudança das condições de produção - os locutores, os leitores, a situação científica, religiosa e política - os comentários, através da acomodação científica, restabelecem o equilíbrio (o mesmo), produzindo uma correção de perspectiva. (op.cit., p.116).

Com base no exposto acima, pode-se afirmar que, no caso das edições revistas, as notas do Autor e os Prefácios procuram situar a inscrição dessas edições em um processo discursivo mais amplo, atestando com isto a abertura do texto à exterioridade constitutiva. O espaço dessas notas e prefácios joga, portanto, com a historicidade do texto ao explicitar a mudança das condições de produção no que concerne a cada uma das edições em tela: estão fortemente em jogo, como se constata, as relações contextuais (dentre aquelas apontadas por Indursky, 2001), entendendo-se por elas o contexto sócio-histórico. Ora, o fato é que o sujeito não tem como negar que 
anteriormente construiu de modo diverso o livro que ali está, e por aí se instaura uma contradição no processo de reformular o texto. Isto porque, se por um lado, é necessária a evidência ideológica de um novo texto homogêneo, por outro, é igualmente necessário desconstruir o efeito-texto da edição de partida (EP) na edição revista (ER) e, ao fazer isto, o sujeito, consciente ou não disso, acaba por igualmente fazer esvaecer o efeito-texto da ER. Como lembra Solange Gallo sobre este aspecto do funcionamento da autoria,

A assunção da autoria pelo sujeito [...] consiste, em última análise, na assunção da "construção" de um "sentido" e de um "fecho" organizadores de todo o texto. Esse "fecho", apesar de ser um entre tantos outros possíveis produzirá, para o texto, um efeito de sentido único, como se não houvesse outro possível. Ou seja, esse "fecho" torna-se "fim" por um efeito ideológico produzido pela "instituição" onde o texto se inscreve: o efeito que faz parecer “único” o que é “múltiplo”, "transparente” o que é “ambíguo” (1992, p.58).

Acreditamos que, embora as reflexões de Gallo tenham sido construídas com base em análises de produções textuais de alunos, podemos deslocar para cá a passagem acima, uma vez que tratam, antes de outra coisa, do funcionamento do efeito-autor sobre um texto. Falávamos a respeito dos Prefácios e Notas do Autor, e é precisamente aqui que gostaríamos de ir adiante e colocar as seguintes indagações: ainda que apareçam no início de livros, não serão os prefácios e as notas do Autor, também eles, uma espécie de efeito-fecho de um livro que já aparece ao sujeito como ilusoriamente fechado? Emerge então a dialética entre mesmo e outro, com a pergunta: o que costuma fazer o prefácio da EP na ER (exceto no caso de apagamento já referido)? Por que a repetição e, frequentemente, a existência de dois prefácios distintos? Ora, considera-se no âmbito da formação social, que, embora seja uma outra edição, o livro, enquanto livro $X$ imputado a um autor $\mathrm{Y}$, permanece sendo o mesmo. E quanto ao sujeito, por sua vez, que exerce a função enunciativa de autor, mantém-se na ilusão do mesmo, "esquecendo" que até a repetição ipsis litteris faz de uma formulação uma outra.

Formulações idênticas? Diferentes? Que livros são estes, afinal? O que pensar da edição revista na relação entre versões? Trata-se ainda do mesmo livro? De outro disfarçado sob o mesmo-antigo título? De um livro cuja identidade é contraditória?

\section{O ESTATUTO DA EDIÇÃO REVISTA EM ANÁLISE DO DISCURSO}

O processo discursivo aqui tomado como objeto de reflexão comporta constitutivamente em seu funcionamento a sucessão, a simultaneidade e a permanência. Há uma dialética entre, de um lado, a sucessão de certos saberes e tomadas de posição (os quais perdem seu posto em prol da hegemonia de saberes e posicionamentos emergentes), e, de outro, a simultaneidade de sentidos, logo, também dos posicionamentos que os atribuem. Tal dialética converge em direção à permanência típica da ordem do discurso. Ora, segundo diz Pêcheux em "Analyse Automatique du Discours” (1969, trad.bras. "Análise Automática do Discurso”, 1993), todo discurso é parte de um processo discursivo contínuo e mais amplo. Há, pois, um processo único (qual seja, a própria ordem do discurso) no interior do qual se inscrevem, em diferentes condições sócio-históricas, EP e ER.

A ordem do discurso é em si mesma inapreensível e só pode ser tomada através de objetos simbólicos (os livros, no caso) que, ao recortarem-na sócio-historicamente e materializarem-na linguisticamente, a trazem como um elemento constitutivo de suas próprias existências. Nessa perspectiva, não são propriamente as edições que se sucedem (aliás, elas coexistem, apesar da 
ilusão de que uma invalida a outra); o que ocorre é a sucessão de uma dada relação "sujeitosaber-ideologia na conjuntura X" por uma outra relação "sujeito-saber-ideologia na conjuntura Y”. Diante disso, a permanência assegura a reprodução do "mesmo", enfim, sua repetição, pois mudar totalmente os saberes seria trocá-los de formação discursiva, o que é inconcebível, pois se ocorresse, estar-se-ia diante da desidentificação própria a uma ruptura epistemológica (Pêcheux, 1975/1988), e não de um redimensionamento interno (reformulação teórica). Embora não seja radical como a ruptura, a reformulação também se refere a um "ponto sem regresso" (Pêcheux; Fichant, 1969/1971) ${ }^{6}$, a partir do qual se pretende instaurar a impossibilidade de retomada de certas parcelas de saber precedentes. No entanto, é por haver ainda algo de permanente - o repetível - que podem surgir diferentes modos de enunciar, sem que com isto se desfigure a relação do sujeito com o domínio de saber. A descontinuidade com certos modos de enunciar, por sua vez, engendrada pela sucessão acima referida, sinaliza a dispersão pelo jogo entre memória e esquecimento.

Tomado na teia das contradições históricas do campo em que se constitui, o sujeito entra num jogo de repetir/deslocar/esquecer, procedimentos estes aos quais cabe a metáfora topológica do nó, já que eles formam um verdadeiro nó na materialidade textual da edição revista. Esta última então se desdobra num gesto simultâneo de proximidade e distanciamento quanto à edição anterior: proximidade em virtude das determinações ideológicas que ainda permitem a manutenção da parcela repetível de saberes; distanciamento em virtude de tudo o que, uma vez precisando ser esquecido, deve ser ressignificado, embora subterraneamente retorne enquanto avesso do intradiscurso.

Considerar a contradição instaurada no interior de um campo de saber pelo viés da contraidentificação subjetiva, abre espaço para a emergência do outro, esquecido, que, paradoxalmente, se mostra e se esconde sob a materialidade da edição revista. À moda do episódio de Clémentis como Jean-Jacques Courtine (1982/1999) resgata de Kundera -, episódio pelo qual Clémentis, ainda que apagado da fotografia, faz-se nesta ainda presente memorial e materialmente por seu chapéu, que emprestara a Gottwald ${ }^{7}$, da mesma forma a edição de partida se faz assim presente apesar da pretensão de que possa ser apagada em prol da edição revista. Nesta, aquela se mostra presente, mas transformada; ou ainda, presente pela necessidade de que se a esqueça; deve-se trazê-la à tona para dizer que ela já não funciona mais como algo que "faz sentido ser publicado e academicamente mencionado”; enfim, para justificar antes da substituição, a diferença e a primazia da nova. Lembremos, então, o que diz Foucault em L'archéologie du savoir (1969, ed. bras. Arqueologia do Saber, 2007, p.28): "nossa razão é a diferença dos discursos, nossa história a diferença dos tempos, nosso eu a diferença das máscaras. [...] a diferença, longe de ser origem esquecida e recoberta, é a dispersão que somos e que fazemos”.

Mesmo situado no interior do confronto entre o que podia/devia ser dito antes e aquilo que pode/deve ser dito agora, o sujeito procura construir uma unidade de sentido fechada, da qual os sentidos possam emergir como evidentes, como se não houvessem sido outros. Se, por um lado, a homogeneidade ilusória da ER emerge enquanto condição sine qua non de sua leitura, por outro,

\footnotetext{
${ }^{6}$ A questão da ruptura epistemológica é desenvolvida por Michel Pêcheux e Michel Fichant em Sur le histoire des sciences (1969, ed.port. Sobre a história das ciências, 1971).

${ }^{7}$ O episódio é citado por Courtine em “La toque de Clémentis” (1982, trad.bras. “O chapéu de Clémentis”, 1999): em Praga, Fevereiro de 1948, o dirigente comunista Gottwald discursava para uma multidão. Como fazia muito frio, Clémentis, muito próximo do líder, tirou o chapéu e o emprestou a Gottwald. A cena em que este último, usando o tal chapéu, discursava para o povo, foi registrada pelo departamento de fotografia e amplamente divulgada; porém, quatro anos mais tarde, Clémentis foi acusado de traição, e o referido departamento, então, rapidamente o apagou da foto, sem, no entanto, tirar de Gottwald o chapéu.
} 
desde o próprio desdobramento inicial do livro (em notas do Autor e/ou em prefácios) já se pode flagrar a instauração de buracos: a palavra denuncia a equivocidade do sentido; o discurso, a heterogeneidade da formação discursiva; o novo posicionamento do sujeito, a cisão da ideologia.

A edição revista desconstrói a unidade aparente da edição de partida; ao fazê-lo atestando a incompletude desta, acaba por acentuar sua própria. Dessa forma, a edição revista tanto não preencherá todas as lacunas da edição de partida, quanto será, também ela, um texto repleto de lacunas. É a contradição que a constitui que leva à necessidade de um espaço no qual se possa expor algo a respeito do processo de reformulação do livro: ora, de uma forma ou de outra, a responsabilidade atribuída pela sociedade ao sujeito-autor exige uma justificativa quanto a um livro que é, na verdade, um outro sob a aparência do mesmo, e mais: um outro que figura inclusive sob o mesmo título. O livro, então, desdobra-se tecendo um comentário de si e de seu avesso, isto é, de si enquanto "edição revista" e daquele que ele era, emergindo assim a dialética entre o que ele é e o que ele não é mais, entre o que ele pode e o que não pode prosseguir dizendo, engendrando-se por aí um embate entre as diferentes posições ideológicas que, por sua vez, revelam a contradição inerente ao "lugar discursivo" de onde enuncia o sujeito.

O ponto essencial que autoriza a referir o processo discursivo de reformulação de livros enquanto algo radicalmente contraditório, reside em que não se trata de opor uma edição $\mathrm{X}$ à sua edição revista $\mathrm{Y}$, mas de fazer equivaler, como sendo semelhantes de modo geral (ou seja, no "pensamento diretor”), duas edições internamente distintas. A forma - o título - permanece materialmente repetida; porém, seu sentido é outro e, por isso, defendemos que o livro é outro. Tomemos este exemplo: Moderna Gramática Portuguesa. O que significa Moderna em 1987, quanto às mais recentes pesquisas científicas, não pode ser idêntico ao que significa Moderna em 2005. E nessa direção, tampouco Gramática pode significar a mesma coisa diante dos avanços dos estudos linguísticos.

É com esses argumentos que justificamos nossa crença em que não há possibilidade de dizer que os livros sejam efetivamente equivalentes, mas, isto sim, se pode e se deve pontuar sua irrepetibilidade. Ora, reforça-se isto com o fato de que as condições de produção de cada uma das edições são singulares, portanto, irrepetíveis. Tal constatação, no entanto, não é evidente; pelo contrário: resulta da ultrapassagem analítica de uma série de efeitos ideológicos, ou seja, é porque se analisou o processo de reformulação de livros desde um ponto de vista que defendeu o irrepetível aliado à incompletude e à heterogeneidade, que se pôde desfazer a ilusão identitária sugerida pelo título das publicações examinadas. Lembremos que atribuir um nome a alguém ou a algo é engendrar uma possibilidade de singularizar a entidade nomeada, tanto quanto é responder a “o que ou quem é X?”; e, nesse contexto, o nome é jurídico, ao passo que a unidade que ele designa, porém, é não mais do que imaginária. Por trás da repetição aparentemente transparente do título, esconde-se a profunda opacidade do discurso; o confronto entre enunciável e não-mais-enunciável; o fantasma do outro a espreitar o um; a errância de sentidos deslizantes, desviados, esquecidos. Esquecimento imbuído de memória.

Joga-se com o contato e o confronto entre o visível e o não visível (mas nem por isso invisível); o saber existente e o saber outrora impensado; entre o ainda presente/lembrado e o ausente/esquecido, entre o repetido e o reformulado, por meio das diferentes versões. As análises efetuadas revelaram, assim, a instauração de um confronto ilusoriamente maniqueísta entre "ultrapassado"/“atual”, edição anterior/revista, confronto esse encenado especialmente no palco dos Prefácios e Notas do Autor, os quais advertem o sujeito-leitor e procuram situá-lo não apenas perante as condições de produção da nova edição, mas perante aquelas que marcam a produção de saber, saber este que encontra abrigo sob a forma-sujeito de um determinado domínio cujos posicionamentos ela organiza e reorganiza sem cessar. 


\section{CONSIDERAÇÕES FINAIS}

“Autoria supõe processo, autor impõe produto”, afirma Valdir Flores (2007, p.73) no quadro da Linguística da Enunciação. No presente artigo, porém, pensou-se autoria enquanto função enunciativa ligada ao processo discursivo de reformulação de livros; ao passo que se pensou autor enquanto efeito decorrente de exigências sociais. Para pensar a autoria em Análise do Discurso, é necessário considerar o percurso da escrita e lembrar o fato de que, quando se fala em função enunciativa, tal função deve ser compreendida diferentemente de como a conceberiam as Teorias Enunciativas. È, pois, o percurso em si que se torna relevante para a AD, visto que ele é o que permite compreender o funcionamento discursivo da prática de reformulação de livros.

O trajeto percorrido para analisar o funcionamento da autoria em nosso objeto de reflexão apontou que a grande problemática colocada em cena pelo processo discursivo examinado reside na identidade da edição revista, edição esta que, como vimos, não tem de idêntico à anterior nem sequer o título, já que este, ainda que repetido ipsis litteris, significa de um modo radicalmente outro.

Referir a reformulação enquanto processo discursivo autorizou a inscrever a edição revista, assim como a edição de partida, na historicidade da ordem do discurso e, deste modo, pensar os redimensionamentos internos de domínios de saber. Nessa direção, o acontecimento enunciativo - conceito concebido por Indursky (2008) - emergiu como uma noção-pivô da reflexão, visto que não só ele instaura o processo discursivo examinado, mas, igualmente, fomenta a continuidade do campo de conhecimento no interior do qual surge; ele instaura novas filiações de sentido e com isso reconfigura as redes de memória, fazendo trabalhar as fronteiras do enunciável de uma dada formação discursiva. Pôde-se, pois, entrever através de análises o papel desse acontecimento nas disputas interpretativas das quais a edição revista é o palco privilegiado... até que ela se torne uma edição de partida e também figure no memorial de uma outra edição.

Cabe resgatar o que afirma Edward Lopes (1997, p.46): "Certamente, um livro de ciência não vale pelo que ele fixa, mas pelo que ele põe em movimento; não pelo que ele colhe, mas pelo que semeia". E continua, então, o referido autor: "Sabemos todos bem que o futuro é caprichoso e se compraz em entortar hoje o que ontem pareceu correto e em endireitar amanhã o que hoje nossa miopia entorta” (ibid.). A produção de conhecimento, na medida em que é parte de um processo discursivo mais amplo, existe em constante mutação, prova incontestável de que, antes de outra coisa, ela envolve sujeitos e prática de linguagem, enfim, palavras em movimento, discursos.

\section{REFERÊNCIAS}

COURTINE, Jean-Jacques. O chapéu de Clémentis. Trad. por Marne R. Rodrigues. In: INDURSKY, F.; LEANDRO FERREIRA, M.C. (Orgs.). Os múltiplos territórios da Análise do Discurso. Porto Alegre: Sagra-Luzzatto, 1999. p.15-22. (Trad. de: La toque de Clémentis, 1982)

FLORES, Valdir N. Escrita, Enunciação e Autoria. In: CAZARIN, E.A.; RASIA, G.S. (Orgs.) Ensino e Aprendizagem de Línguas - Língua Portuguesa. Ijuí: UNIJUÍ, 2007. p.69-80.

FOUCAULT, Michel. A ordem do discurso. Trad. por Laura F. de A. Sampaio. 3.ed. São Paulo: Loyola, 2006. (Trad. de: L'ordre du discours, 1971) 
. Arqueologia do Saber. 7.ed., 2.reimpr. Trad. por Luiz F.B. Neves. Rio de Janeiro: Forense Universitária, 2007. (Trad. de: L’archéologie du savoir, 1969)

GALLO, Solange. Discurso da Escrita e Ensino. Campinas: Unicamp, 1992.

INDURSKY, Freda. Da heterogeneidade do discurso à heterogeneidade do texto e suas implicações no processo da leitura. In: ERNST-PEREIRA, A.; FUNCK, S.B. (Orgs.). A leitura e a escrita como práticas discursivas. Pelotas: Educat, 2001. p.27-42.

. Unicidade, desdobramento, fragmentação: a trajetória da noção de sujeito em Análise do Discurso. In: MITTMANN, S.; CAZARIN, E.; GRIGOLETTO, E. (Orgs.) Práticas discursivas e identitárias - Sujeito e língua. Porto Alegre: UFRGS, 2008. p.9-33.

LOPES, Edward. A Identidade e a Diferença - Raízes Históricas das Teorias Estruturais da Narrativa. São Paulo: EDUSP, 1997.

ORLANDI, Eni P. Terra à vista - Discurso do confronto: Velho e Novo Mundo. São Paulo: Cortez; Campinas: Unicamp, 1990.

Discurso e texto. Formulação e circulação dos sentidos. Campinas: Pontes, 2001.

Análise de Discurso: princípios \& procedimentos. 7.ed. Campinas: Pontes, 2007.

PÊCHEUX, Michel. Semântica e discurso: uma crítica à afirmação do óbvio. Trad. por Eni P. Orlandi [et al.]. Campinas: Unicamp, 1988. (Trad. de: Les Vérités de La Palice, 1975) Análise automática do discurso. Trad. por Eni P. Orlandi. In: GADET, F.; HAK, T.

(Orgs.). Por uma análise automática do discurso: uma introdução à obra de Michel Pêcheux. 2.ed. Campinas: Unicamp, 1993. p.61-161. (Trad. de: Analyse automatique du discours, 1969)

. Ler o arquivo hoje. Trad. por $\mathrm{M}^{\mathrm{a}}$ das Graças L.M. do Amaral. In: ORLANDI, E.P. (Org.) Gestos de Leitura - Da história no discurso. 2.ed. Campinas: Unicamp, 1997. p.55-66. (Trad. de: Lire l'archive aujourd'hui, 1982)

. Papel da memória. In: ACHARD, P. [et al.]. Papel da Memória. Trad. e introd. de José H. Nunes. Campinas: Pontes, 1999. p.49-57. (Trad.de: Rôle de la mémoire, 1983)

.; FICHANT, Michel. Sobre a história das ciências. Trad. por Francisco Bairrão. Lisboa: Estampa, 1971. (Trad. de: Sur l'histoire des sciences, 1969)

.; FUCHS, Catherine. A propósito da análise automática do discurso: atualizações e perspectivas. Trad. por Péricles Cunha. In: GADET, F.; HAK, T. (Orgs.). Por uma análise automática do discurso: uma introdução à obra de Michel Pêcheux. 2.ed. Campinas: Unicamp, 1993. p.163-252. (Trad. de: Mises au point et perspectives à propos de l'analyse automatique du discours, 1975)

SILVA, Adriana P.L.V. Entretextualidade nas fronteiras do enunciável: um olhar sobre o processo discursivo de reformulação de livros. Porto Alegre: UFRGS, 2009. (Dissertação de Mestrado)

ZANDWAIS, Ana. A forma-sujeito do discurso e suas modalidades de subjetivação: um contraponto entre saberes e práticas. In: INDURSKY, F.; FERREIRA, M.C.L. (Orgs.). Michel Pêcheux e a análise do discurso: uma relação de nunca acabar. São Carlos: Claraluz, 2005a. p.143-156.

. Relações entre a Filosofia da Práxis e a Filosofia da Linguagem sob a ótica de Mikhail Bakhtin: um discurso fundador. In: (Org.). Mikhail Bakhtin:Contribuições para a Filosofia da Linguagem e Estudos Discursivos. Porto Alegre: Sagra-Luzzatto, 2005b. p.83100. (Col. Ensaios, v.20) 
BECHARA, Evanildo. Moderna Gramática Portuguesa. 31.ed. São Paulo: Cia. Ed. Nacional, 1987.

Moderna Gramática Portuguesa. 37.ed.rev.ampl., 15.reimpr. Rio de Janeiro: Lucerna, 2005.

FERNANDES, Florestan. Sociedade de classes e subdesenvolvimento. Rio de Janeiro: Zahar, 1968.

Sociedade de classes e subdesenvolvimento. 2.ed.rev. Rio de Janeiro: Zahar, 1972.

ROCHA LIMA, Carlos H. Gramática normativa da Língua Portuguesa. 4.ed. Rio de Janeiro: F.Briguiet \& Cia., 1959.

Gramática normativa da Língua Portuguesa. 15.ed. (refundida). Rio de Janeiro: J. Olympio, 1972.

TODOROV, Tzvetan. Estruturalismo e Poética. Trad. por José P. Paes. São Paulo: Cultrix, 1970. . Estruturalismo e Poética. 4.ed.rev.ampl. cf. ed. franc. de 1973. Trad. por José P. Paes e Frederico P. de Barros. São Paulo: Cultrix, 1976. 